\title{
Transfer of Murine Host Protection by Using Interleukin-2- Dependent T-Lymphocyte Lines
}

\author{
CASSANDRA C. PAUL† AND RANDALL A. SMITH* \\ Department of Microbiology and Immunology, College of Science and Mathematics and School of Medicine, \\ Wright State University, Dayton, Ohio 45435
}

Received 21 March 1988/Accepted 18 May 1988

\begin{abstract}
We have demonstrated in this study that long-term, interleukin-2 (IL-2)-dependent, salmonella antigenspecific $T$-lymphocyte lines, as well as peritoneal exudate-enriched $T$ cells, could be developed from both the antigen-sensitized inguinal and periaortic lymph nodes. Only those lines (salmonella-specific lymph node cells or peritoneal exudate $T$ cells) were capable of adoptively transferring significant host protection $(P<0.01)$ compared with the immune reactions of lethally challenged naive controls or of mice that had ovalbuminspecific T-cell lines transferred. Of particular interest was the finding that IL-2-dependent T-cell lines derived from the lymph nodes could only confer host protection to naive mice when both the transfer and challenge dose were administered via the intravenous route. Likewise, those $T$-cell lines derived from the peritoneal exudate were only capable of adoptively transferring significant protection when the cells and challenge dose of salmonellae were administered intraperitoneally. These studies indicate that systemic host protection can be transferred to naive mice, but depending on the source, the IL-2-dependent T-cell lines (lymph node or peritoneally isolated) functioned differentially upon challenge. Also, the results of this study indicate that the administration of greater numbers of IL-2-specific $T$ cells may result in decreased, rather than enhanced, host protection. This may be due to the fact that the IL-2-dependent T-cell population consisted of 20 to $25 \%$ Lyt- $2,3^{+}$cells, indicating that cells of the suppressor/cytotoxic phenotype were present. Thus, increasing the number of cells transferred may result in an abrogation of protection.
\end{abstract}

T lymphocytes are central in immune reactions, such as cellular cytotoxicity, delayed hypersensitivity, graft-versushost reactivity, antibody production, immune tolerance, and allotypic suppression. The ability to expand antigen-specific $\mathrm{T}$ lymphocytes has allowed more opportunity for in vitro and in vivo studies of various immune functions. It has been demonstrated that $\mathrm{T}$ lymphocytes can proliferate and functionally differentiate in an antigen-specific fashion (23). The use of such expanded $T$ cells in adoptive transfer studies has not always provided evidence of effective or appropriate in situ activities without certain modifications of the experimental design (e.g., change in numbers or route of administration of the transferred cells) $(12,14)$.

This laboratory has isolated and partially characterized Salmonella antigen-specific T-cell lines (20). In attempts to test the relevance of demonstrated in vitro activities to in vivo function, adoptive transfer studies were performed. Such studies have been useful in investigating the role(s) of $\mathrm{T}$-cell lines directed against other facultative intracellular parasites (12). With the advent of techniques permitting the in vitro enrichment of antigen-specific $T$ cells and subsequent adoptive immunotherapy studies, new areas of investigation have been opened. The observed lack of correlation between in vitro abilities and in vivo activity has been ascribed to aberrant migratory patterns $(1,3,7,8,18)$. Kaufmann (11) reported that high numbers of adoptively transferred T-cell clones were required for systemic delayedtype hypersensitivity transfer, while lower numbers were capable of local subcutaneous antibacterial protection against the facultative intracellular parasite Listeria monocytogenes. It was suggested that the failure of the T-cell

\footnotetext{
* Corresponding author.

$\dagger$ Present address: Department of Medicine, Wright State University VA Campus, Dayton, $\mathrm{OH} 45428$.
}

clones to confer significant protection was because the in vitro-maintained cells had an altered migration pattern. Such phenomena have been reported by others as well $(1,7,8$, 16). We show that in vitro-reactive $T$-cell lines vary in their abilities to adoptively transfer host protection in lethally challenged BALB/c mice. It is reported herein that antigenspecific $\mathrm{T}$ cells derived from peritoneal exudates and those derived from lymph nodes are only capable of transferring significant protection when the route of transfer is intraperitoneal (i.p.) and intravenous (i.v.), respectively.

\section{MATERIALS AND METHODS}

Animals. Female BALB/c mice (6 to 10 weeks of age) were obtained from Harlan Laboratories, Indianapolis, Ind., and were housed in the Animal Resources Laboratory at Wright State Univeristy.

Bacteria. Salmonella typhimurium RIA and SR-11 were grown to $\log$ phase (approximately $10^{9} / \mathrm{ml}$ ) in brain heart infusion broth and diluted appropriately in sterile saline for use.

Antigens. Spent medium antigen (SMA) was prepared from $S$. typhimurium RIA (vaccine strain) according to Cohn (4), and as modified by Collins and Mackaness (5) and Plant and Glynn (21). The SMA was divided into aliquots and stored at $-20^{\circ} \mathrm{C}$ until needed. Ovalbumin (OVA; Sigma Chemical Co., St. Louis, Mo.) was used to prepare and maintain OVA antigen-specific lymph node T-cell lines.

Generation of SMA-specific LNCs. Antigen-specific T lymphocytes from the lymph nodes were prepared essentially according to Corradin et al. (6), with some modifications as described by Kaufmann et al. (14). Briefly, the mice were injected subcutaneously at the base of the tail with $25 \mu \mathrm{g}$ of SMA emulsified in complete Freund adjuvant. After 7 days, the periaortic and inguinal lymph nodes were aseptically removed and a single-cell suspension was prepared in RPMI 
1640 with $25 \mathrm{mM}$ HEPES ( $N$-2-hydroxyethylpiperazine- $N^{\prime}-$ 2-ethanesulfonic acid) (MA Bioproducts, Walkersville, Md.), supplemented with $5 \%$ fetal bovine serum (Hyclone Laboratories, Logan, Utah). The lymph node cell (LNC) suspension was placed in a $15-\mathrm{ml}$ conical centrifuge tube (Corning Glass Works, Corning, N.Y.) and placed on ice for $20 \mathrm{~min}$. The cell suspensions were then centrifuged at $250 \times$ $g$ for $10 \mathrm{~min}$. The cell pellet was suspended in complete T-cell medium (CTCM): RPMI 1640 with 25 mM HEPES, $10 \%$ fetal bovine serum, $5 \times 10^{-5} \mathrm{M}$ 2-mercaptoethanol, 2 $\mathrm{mM}$ L-glutamine (MA Bioproducts), and $50 \mu \mathrm{g}$ of gentamicin per $\mathrm{ml}$. The cells were counted and adjusted to a concentration of $2 \times 10^{5} / \mathrm{ml}$. Aliquots of $1 \mathrm{ml}$ of the cell suspension were plated in wells of a 24-well plate (Costar, Cambridge, Mass.) in the presence of $50 \mu \mathrm{g}$ of SMA for 4 days at $37^{\circ} \mathrm{C}$ in a $5 \% \mathrm{CO}_{2}$ incubator. At the conclusion of this incubation period, the contents of the wells were aspirated and layered onto Histopaque (density, 1.077; Sigma). This cell gradient was centrifuged at $300 \times g$ for $15 \mathrm{~min}$. The cells at the interface were aspirated and washed in RPMI 1640, supplemented with $5 \%$ fetal bovine serum. The cell pellet was suspended at $2 \times 10^{5} / \mathrm{ml}$ in CTCM. The in vitro antigenexpanded cells were cultured with interleukin-2 (IL-2; Genzyme Corporation, Boston, Mass.) at $10 \mathrm{U} / 10^{5}$ cells for 4 days at $37^{\circ} \mathrm{C}$ in $5 \% \mathrm{CO}_{2}$. At the conclusion of this period, the viable blastlike cells were again enriched by layering onto Histopaque and harvesting the cells at the interface. These antigen-reactive cells were then cultured in the presence of antigen at $40 \mu \mathrm{g}$ of SMA per $2 \times 10^{5}$ antigen-reactive cells and $6 \times 10^{5}$ irradiated syngeneic splenic feeder cells. The cycle of antigen and feeder cells was repeated once every 7 days, with exogenous IL-2 supplied every 14 days.

Generation of OVA antigen-specific T-cell lines. As a control for the adoptive transfer studies, OVA antigen-specific, continuous, IL-2-dependent $\mathrm{T}$ lines were produced and maintained. All procedures involved in the isolation of the stimulated LNCs, culturing, and addition of feeder cells and IL-2 were identical to those used for the generation of SMA T-cell lines, with the following exceptions: the mice were injected with a 50- $\mu$ g dose of OVA to sensitize the T cells and $50 \mu \mathrm{g}$ of OVA was used as the concentration of antigen to maintain the $\mathrm{T}$ cells in vitro.

Immunization and isolation of PETLEs. The method of Schwartz et al. (22) was followed for the immunization of the mice, removal of the cells, and the enrichment for peritoneal exudate T-lymphocyte-enriched cells (PETLEs). Briefly, female BALB/c mice were immunized i.p. with $4 \times 10^{4}$ live bacteria of the RIA vaccine strain. After 7 days, the mice received an additional i.p. injection of $2 \times 10^{5}$ live RIA bacteria. After 5 days, a peritoneal exudate was induced by an i.p. injection of $0.5 \mathrm{ml}$ of a $10 \%$ Difco Proteose Peptone solution (Difco Laboratories, Detroit, Mich). The mice were sacrificed 3 days later, and the peritoneal cells were harvested by washing the peritoneums of the animals with RPMI 1640 containing $50 \mu \mathrm{g}$ of gentamicin per $\mathrm{ml}$. The peritoneal cells were pelleted by centrifugation at $250 \times g$ for $10 \mathrm{~min}$ and suspended at a concentration of $1 \times 10^{8}$ to $2 \times$ $10^{8} / \mathrm{ml}$ in RPMI 1640 containing $5 \%$ fetal bovine serum and $50 \mu \mathrm{g}$ of gentamicin per $\mathrm{ml}$. The cells were then applied to a nylon wool column by the method of Julius et al. (10). The nonadherent (T-enriched population) cells were centrifuged $(200 \times g$ for $10 \mathrm{~min})$ and suspended at $10^{6} / \mathrm{ml}$ in CTCM. These PETLEs were plated at a concentration of $2 \times 10^{5}$ with $6 \times 10^{5}$ irradiated splenic feeders and $40 \mu \mathrm{g}$ of SMA. The PETLEs required periodic washing and subsequent replacement of the antigen-presenting cells and antigen, with
IL-2 being added to the cultures on alternate feeder cell additions (i.e., same cycling as with the $\mathrm{T}$ cells derived from the lymph nodes).

Cell surface phenotyping. For this procedure, $10^{6} \mathrm{LNCs}$ or PETLEs were isolated from the Histopaque gradient and subsequently washed using serum-free RPMI 1640. After this wash, the cells were suspended in a total volume of 100 $\mu l$ of the appropriate antiserum, which was diluted in phosphate-buffered saline (PBS; $\mathrm{pH} 7.2$ ) containing $0.1 \%$ sodium azide. After an incubation period of $45 \mathrm{~min}$ at $4^{\circ} \mathrm{C}$, the cells were washed gently two times using PBS containing $0.1 \%$ sodium azide. The antisera used were Thy-1.2 (Accurate Chemicals, Westbury, N.Y.), Lyt-2-biotin conjugate, and Lyt-1-biotin conjugate (Becton Dickinson and Co., Sunnyvale, Calif.). The indicator fluorochrome used was avidinfluorescein isothiocyanate conjugate (Becton Dickinson). For those procedures which required dual labeling, avidinrhodamine isothiocyanate conjugate (Becton Dickinson) was used to detect those cells which bound the Lyt-2-biotin conjugate, and a direct Lyt-1-fluorescein isothiocyanate (Becton Dickinson) was utilized to detect the Lyt-1-positive populations. At the conclusion of the 45 -min labeling period, the cells were washed twiced in PBS containing $0.1 \%$ sodium azide. After the last wash, the cells were suspended in $100 \mu \mathrm{l}$ of the appropriate fluorochrome (the only exception to this being when a direct labeling was used) and were incubated at $4^{\circ} \mathrm{C}$ in the dark for an additional $45 \mathrm{~min}$. Following two washes in PBS containing $0.1 \%$ sodium azide, the cells were suspended in $100 \mu \mathrm{l}$ of mounting medium (mixture of PBS and glycerol, $1: 1)$. Aliquots $(20 \mu \mathrm{l})$ were placed onto glass slides, and fields containing approximately 200 cells were viewed and screened for those cells expressing positive membrane fluorescence by using a fluorescence microscope.

Preparation of irradiated splenic feeders. For the syngeneic feeder populations, BALB/c mice were sacrificed by cervical dislocation, and their spleens were aseptically removed. A single-cell suspension was prepared in RPMI 1640 supplemented with $1 \%$ fetal bovine serum. The cell suspension was adjusted to a concentration of $5 \times 10^{6} / \mathrm{ml}$, and 5 -ml aliquots were placed into $25-\mathrm{cm}^{2}$ tissue culture flasks (Corning). The spleen cell suspension was irradiated with 2,000 rads by using a Faxitron X-ray unit (Hewlett-Packard Co., McMinnville, Oreg.). Following the irradiation, the cells were washed three times with RPMI containing $5 \%$ fetal bovine serum and were then suspended in CTCM. The cells were counted, and the viability was determined by using a 1-ppm $(\mu \mathrm{g} / \mathrm{ml})$ solution of acridine orange and ethidium bromide (19).

Adoptive transfer using LNCs. The in vitro-maintained T cells were centrifuged over Histopaque. The viable cells at the interface were suspended at $10^{7} / \mathrm{ml}$ in Hanks balanced salt solution. The mice received $10^{6} \mathrm{~T}$ cells in a volume of $100 \mu \mathrm{l}$ i.v. through the dorsal tail vein. After $3 \mathrm{~h}$, the adoptively transferred group, as well as the controls, received an i.v. challenge with the virulent $S$. typhimurium SR-11. The animals were observed for 30 days, after which the survival data were analyzed for significance by using the chi-square test.

Adoptive transfer using PETLEs. The PETLEs maintained in vitro for prolonged periods were prepared as were the LNCs. The mice received $10^{6}$ PETLEs i.p. or i.v. in $100 \mu \mathrm{l}$ of Hanks balanced salt solution. The animals were challenged with various numbers of $S$. typhimurium SR-11, presented either i.p. or i.v. The mice were observed for $\mathbf{3 0}$ days, and survival data were analyzed for significance by using the chi-square test. 
TABLE 1. Adoptive transfer of host protection by using lymph node-derived T-cell lines

\begin{tabular}{lcc}
\hline $\begin{array}{c}\text { Cells } \\
\text { transferred }^{a}\end{array}$ & $\begin{array}{c}\text { No. of } \\
\text { challenge } \\
\text { doses }\left(\mathrm{LD}_{50} \mathrm{~s}\right)\end{array}$ & $\%$ Survival $^{b}$ \\
\hline None & 10 & $0(0 / 20)$ \\
LNC OVA & 10 & $10(2 / 20)^{c}$ \\
LNC RIA & 10 & $68(13 / 20)^{d . e}$ \\
LNC RIA & 10 & $10(1 / 10)^{c}$ \\
None & 20 & $0(0 / 10)$ \\
LNC OVA & 20 & $0(0 / 10)$ \\
LNC RIA & 20 & $50(5 / 10)^{d}$ \\
\hline
\end{tabular}

${ }^{a}$ Adoptively transferred mice received $10^{6} \mathrm{~T}$ cells i.v., followed $3 \mathrm{~h}$ later with an i.v. salmonella challenge.

${ }^{b}$ The values in the parentheses are the number of mice surviving 30 days postchallenge/number of mice injected.

c Not significant compared with the control group of mice.

${ }^{d} P<0.01$ compared with the survival of naive challenged mice.

e $P<0.01$ compared with the survival of mice adoptively transferred with the OVA-specific T cells.

${ }^{f}$ Mice were injected with $5 \times 10^{6} \mathrm{LNC}$ RIA T cells by the i.v. route prior to being challenged with virulent salmonellae.

\section{RESULTS AND DISCUSSION}

The results of the adoptive transfer studies using lymph node-derived $\mathrm{T}$ cells are reported in Table 1 . The nonvaccinated naive controls demonstrated marked susceptibility to the pathogen, $S$. typhimurium. All of the control animals were dead by 7.6 days postchallenge in the group receiving $1050 \%$ lethal doses $\left(\mathrm{LD}_{50} \mathrm{~s}\right)$ or by 7.3 days in the group receiving $20 \mathrm{LD}_{50} \mathrm{~s}$. However, $10 \%$ of the OVA T-celltransferred mice did survive the challenge infection. Possibly these cells were producing lymphokines, such as IL-2 or gamma interferon, which allowed for some transient activation of the immune system. The RIA SMA-maintained T-cell lines were able to confer a significant survival advantage ( $P$ $<0.01$ compared with the controls using the chi-square analysis), with $68 \%$ of the mice surviving the $10 \mathrm{LD}_{50} \mathrm{~s}$ of salmonellae and $50 \%$ surviving the $20 \mathrm{LD}_{50}$ challenge doses. Thus, the in vitro-maintained pool of $\mathrm{T}$ cells retained their capacity to respond to the RIA SMA and function in vivo in a host-protective manner. These $\mathrm{T}$ cells were not modified to such an extent through the in vitro culturing as to prevent a functional immune response from occurring. Such cell line characteristics have been observed in the murine listeriosis system $(11,13,15)$, as well as in the murine tuberculosis model (17).

When the number of $T$ cells transferred to the naive recipient mice was increased from $1 \times 10^{6}$ to $5 \times 10^{6}$ cells, there was a loss in protective capacity following the i.v. transfer. After performing the phenotyping of the continuous T-cell lines (LNCs or PETLEs), we found that 75 to $80 \%$ of the cells were $\mathrm{Lyt}-1^{+}, 10$ to $12 \%$ were Lyt- $2,3^{+}$, and 2 to $5 \%$ were Lyt $-1,2,3^{+}$. Possibly this decreased protection resulting from the injection of $5 \times 10^{6} \mathrm{~T}$ cells was due to suppressor-T-cell activity, since this phenotype was present in all of our continuous $\mathrm{T}$-cell lines and the mice received five times the number of potential suppressor/cytotoxic cells in this experiment.

In Table 2, the results of adoptive transfer studies using PETLEs are presented. It was also shown in this study that the naive controls were highly susceptible to lethal challenge with the SR-11 strain, with no survivors 30 days postchallenge and a mean survival time of 12.4 days. The survival data presented demonstrate that the immunization protocol used to generate RIA antigen-specific T cells is capable of
TABLE 2. Effectiveness of peritoneally derived T-cell lines in adoptively transferring host protection

\begin{tabular}{cccc}
\hline $\begin{array}{c}\text { Cells transferred and } \\
\text { route of transfer }^{a}\end{array}$ & $\begin{array}{c}\text { Challenge } \\
\text { route }\end{array}$ & $\begin{array}{c}\text { No. of } \\
\text { challenge doses }\end{array}$ & \% Survival ${ }^{b}$ \\
\hline None & i.v. & 10 & $0(0 / 20)$ \\
None & i.p. & 10 & $0(0 / 20)$ \\
PETLEs & i.v. & 10 & $0(0 / 10)$ \\
i.v. & i.p. & 15 & $0(0 / 10)$ \\
i.v. & i.v. & 15 & $10(1 / 10)^{c}$ \\
i.p. & i.p. & 15 & $70(21 / 30)^{d}$ \\
i.p. & i.p. & 30 & $60(18 / 30)^{d}$ \\
i.p. & i.p.
\end{tabular}

${ }^{a}$ Mice adoptively transferred with $10^{6} \mathrm{~T}$ cells.

$b$ The values in the parentheses are the number of mice surviving 30 days postchallenge/number of mice injected.

' Not significant compared with the respective control group.

${ }^{d} P<0.01$ compared with the survival of naive challenged mice.

providing cells which possess significant protective capacity, in that $70 \%$ of the mice survived the $15 \mathrm{LD}_{50} \mathrm{~s}$ and $60 \%$ survived the $30 \mathrm{LD}_{50}$ bacterial challenge doses. The data show that these antigen-specific $T$ cells must, however, be presented in an appropriate way upon adoptive transfer, as protective function was not the same for either route of transfer. Other investigators have observed comparable phenomena $(7,9,11,16)$. The difference in protective capacity of the transferred cells was not due to a difference in virulence of the organism when different routes were used, as all the mice in either control i.v. or i.p. challenge routes were dead 30 days postchallenge (Table 2 ). The difference in observed effectiveness of function of the transferred cells must therefore be due to some quality of the $\mathrm{T}$ lymphocytes themselves.

In order to see if the lymphocytes derived from lymph nodes displayed similar variability in protective capability, further adoptive transfer studies were performed. The results of such experiments are presented in Table 3 . It is evident that a similar phenomenon occurred when the lymph node-derived $T$ cells were transferred i.p. or i.v., with no significant protection conferred when the i.p. route was used. Perhaps an explanation lies in the fact that the lymph node- and peritoneal exudate-derived $\mathrm{T}$ cells require some, as yet unexplained, homing communication interaction in the spleen (upon i.v. transfer or challenge) or the peritoneum (upon i.p. transfer or challenge). As has already been suggested, aberrant migration patterns may result from inappro-

TABLE 3. Effectiveness of lymph node-derived $T$ cells in transferring host protection by different challenge routes

\begin{tabular}{lcc}
\hline $\begin{array}{c}\text { Cells transferred and } \\
\text { route of transfer }\end{array}$ & $\begin{array}{c}\text { Challenge } \\
\text { route }^{b}\end{array}$ & $\begin{array}{c}\% \\
\text { Survival }^{c}\end{array}$ \\
\hline None & i.v. & $0(0 / 10)$ \\
None & i.p. & $0(0 / 10)$ \\
LNC-derived T cells & i.v. & $50(5 / 10)^{d}$ \\
i.v. & i.p. & $0(0 / 10)$ \\
i.p. & i.p. & $10(1 / 10)^{e}$ \\
i.v. & i.p.
\end{tabular}

a Control mice did not receive any $\mathrm{T}$ cells prior to being challenged; other groups of mice were injected with $10^{6} \mathrm{~T}$ cells i.v. or i.p.

${ }^{b}$ Mice were challenged with $10 \mathrm{LD}_{50}$ s of virulent salmonellae i.v. or i.p.

c The values in the parentheses are the number of mice surviving 30 days postchallenge/number of mice injected.

${ }^{d} \boldsymbol{P}<0.01$ compared with the survival of naive challenged mice.

e Not significantly different from the survival of the naive challenged control group of mice. 
priate communication due to in vitro manipulations of the cells $(1,7,8)$.

The results presented herein demonstrate both the potential benefits and difficulties associated with the utilization of the technique of adoptive immunotherapy with antigenspecific $\mathrm{T}$ cells. One approach at overcoming the observed lack of effectiveness has been to administer exogenous IL-2 at the time of transfer of the in vitro-expanded T cells (2). Such an approach does not explain the reasons for observed lack of efficacy of adoptively transferred cells but attempts to further expand the cells in vivo in hopes of improving the chance that enough cells will reach the appropriate sites.

\section{LITERATURE CITED}

1. Carroll, A. M., M. A. Palladino, H. Oettgen, and M. DeSousa. 1983. In vivo localization of cloned Il-2-dependent $\mathrm{T}$ clones. $\mathrm{J}$. Immunol. 76:69-74.

2. Cheever, M. A., P. D. Greenberg, A. Fefer, and S. Gillis. 1982. Augmentation of the anti-tumor therapeutic efficacy of longterm cultured $\mathrm{T}$ lymphocytes by in vivo administration of purified interleukin 2. J. Exp. Med. 155:968-980.

3. Cheever, M. A., P. D. Greenberg, C. Irle, A. Thompson, D. L. Urdal, D. Y. Mochizuki, C. S. Henney, and S. Gillis. 1984. Interleukin 2 administered in vivo induces the growth of cultured T cells in vivo. J. Immunol. 132:2259-2265.

4. Cohn, Z. 1963. The fate of bacteria within phagocytic cells. I. The degradation of isotypically labeled bacteria by polymorphonuclear leukocytes and macrophages. J. Exp. Med. 117:27-42.

5. Collins, F. M., and G. B. Mackaness. 1968. Delayed hypersensitivity and Arthus reactivity in relation to host resistance in Salmonella infected mice. J. Immunol. 101:830-845.

6. Corradin, B. H., H. M. Etlinger, and J. M. Chiller. 1977. Lymphocyte specificity to protein antigens. I. Characterization of the antigen-induced in vitro $\mathrm{T}$ cell-independent proliferative response with lymph node cells from primed mice. J. Immunol. 119:1048-1053.

7. Dailey, M. O., C. G. Fathman, E. C. Butcher, E. Pillemer, and I. Weissman. 1982. Abnormal migration of T lymphocyte clones. J. Immunol. 128:2134-2136.

8. Dailey, M. O., W. M. Gallatin, and I. L. Weissman. 1985. The in vivo behavior of $\mathrm{T}$ cell clones: altered migration due to the loss of lymphocyte surface homing receptor. J. Mol. Cell. Immunol. 2:27-33.

9. Gallatin, W. U., I. L. Weissman, and E. C. Butcher. 1983. A cell surface molecule organ-specific homing of lymphocytes. Nature (London) 304:30-34.

10. Julius, N. H., E. Simpson, and A. Herzenberg. 1973. A rapid method for the isolation of thymus derived murine lumphocytes.
Eur. J. Immunol. 3:645-649.

11. Kaufmann, S. H. E. 1983 . Effective antibacterial protection induced by a Listeria monocytogenes-specific $\mathrm{T}$ cell clone and its lymphokines. Infect. Immun. 39:1265-1270.

12. Kaufmann, S. H. E., and H. Hahn. 1982. Biological functions of $T$ cell lines with specificity for the intracellular bacterium Listeria monocytogenes in vitro and in vivo. J. Exp. Med. 155: 1754-1765.

13. Kaufmann, S. H. E., H. Hahn, and M. M. Simon. 1982. T-cell subsets induced in Listeria monocytogenes-immune mice: Ly phenotypes of $\mathrm{T}$ cells interacting with macrophages in vitro. Scand. J. Immunol. 16:539-542.

14. Kaufmann, S. H. E., M. M. Simon, and H. Hahn. 1979. Specific Lyt $123 \mathrm{~T}$ cells are involved in protection against Listeria monocytogenes and in delayed hypersensitivity to listeria antigens. J. Exp. Med. 150:1033-1038.

15. Kearns, R. J., and E. C. DeFreitas. 1983. In vitro propagation of antigen-specific $\mathrm{T}$ lymphocytes that adoptively transfer resistance to Listeria monocytogenes. Infect. Immun. 40:713-719.

16. Lotze, M. T., B. R. Line, D. J. Mathisen, and S. A. Rosenberg. 1980. The in vivo distribution of autologous human and murine lymphoid cells grown in T cell growth factor (TCGF): implications for adoptive immune therapy of tumors. J. Immunol. 125: 1487-1493.

17. Orme, I. M., and F. M. Collins. 1984. Adoptive protection of the Mycobacterium tuberculosis infected lung. Cell. Immunol. 84: 113-120.

18. Palladino, M. A., K. Welte, M. Carroll, and H. F. Oettgen. 1984. Characterization of interleukin 2 (IL-2)-dependent cytotoxic T-cell clones. V. Transfer of resistance to allografts and tumor grafts requires exogenous IL-2. Cell. Immunol. 86:299-307.

19. Parks, D. R., V. M. Bryan, V. T. Oi, and L. A. Herzenberg. 1979. Antigen specific identification and cloning of hybridomas with a fluorescence-activated cell sorter. Proc. Natl. Acad. Sci. USA 76:1962-1966.

20. Paul, C., K. Shalala, R. Warren, and R. Smith. 1985. Adoptive transfer of murine host protection to salmonellosis with T-cell growth factor-dependent $T$ cell lines. Infect. Immun. 48:40-43.

21. Plant, J. E., and A. A. Glynn. 1976. Genetics of resistance to infection with Salmonella typhimurium in mice. J. Infect. Dis. 133:72-78

22. Schwartz, R. H., L. Jackson, and W. E. Paul. 1975. T-lymphocyte enriched murine peritoneal exudate cells. I. A reliable assay for antigen-induced T lymphocyte proliferation. J. Immunol. 115:1330-1338.

23. Widmer, M. B., D. C. Roopenian, L. W. Biel, and F. H. Bach. 1985. Characterization of alloreactive murine $T$ cell clones in vivo, p. 201. In H. VonBoehmer and W. Haas (ed.), T cell clones. Elsevier, Amsterdam. 